Gut, 1973, 14, 139-142

\title{
Fibreoptic examination of the colon: a review of 255 cases
}

\author{
R. H. TEAGUE, P. R. SALMON, AND A. E. READ \\ From the Department of Medicine, University of Bristol
}

SUMMARY The results of fibreendoscopy of the colon are described in 255 consecutive examinations.

Of the examinations, $26.5 \%$ resulted in a diagnosis being made solely by endoscopy. This included 17 cases of carcinoma, 15 patients with polyps, and 25 patients with inflammatory bowel disease.

The most common reason for referral was undiagnosed rectal bleeding ( 75 cases) and endoscopy alone was successful in diagnosing the probable or definitive source of bleeding in $50 \%$ of the cases referred. It is not yet clear, however, to what extent this figure may reflect the inadequacy of conventional radiology.

A definitive radiological diagnosis was refuted in 11 patients and an unnecessary laparotomy avoided in seven of these.

There is no doubt that fibreoptic colonoscopy increases diagnostic accuracy in large bowel disease and is especially helpful in cases where radiology is either negative or equivocal.

The use of flexible fibreoptic endoscopes for the investigation of disorders of the digestive system is now established (Classen, 1971). Fibreoptic examination of the large bowel has not, however, developed at the same rate, largely due to lack of suitable instruments, the difficulties associated with patient preparation and endoscopic techniques, and agreement as to its ultimate value to the patient.

Recently, however, long colonoscopes have been developed with facilities for four-way or polydirectional distal tip angulation. These features now allow total colonoscopy in the majority of patients (Deyhle and Demling, 1971; Williams, 1972a).

The value of sigmoidoscopy employing a short $(85 \mathrm{~cm})$ colonoscope has already been demonstrated (Dean and Shearman, 1970; Salmon, Branch, Collins, Espiner, and Read, 1971).

We report in this paper our experience in 255 patients with suspected large bowel disease. These examinations have been performed employing three different colonoscopes. Particular attention has been paid to patient and bowel preparation.

\section{Instruments}

Both American (ACM) ${ }^{1}$ and Japanese (Olympus) ${ }^{2}$ instruments have been used. (ACM 9000 PL, Olympus CF-SB, CF-LB).

${ }^{1}$ Medical Supply Association, Crayford, Kent. 'Key-Med Ltd, Stock Lane, Southend-on-Sea.

Received for publication 6 December 1972.
Standard ACM or Olympus light sources were employed. Photography was used extensively for record and teaching purposes. With the Olympus instruments the Olympus Pen F camera was used with automatic exposure control.

In the case of ACM colonoscopes an Olympus Pen FT camera with $70 \mathrm{~mm}$ Zuiko lens, an ACM Littman adaptor and FCB 1000 photographic light source were employed. Kodak high speed ektachrome (EHB 135 Tungsten 3200K or Daylight) film was used.

\section{Patients Studied}

Two hundred and fifty-five patients with suspected large bowel or terminal ileal disease have been investigated. Indications are listed according to the major referring problem as assessed by the physician or surgeon in charge of the case (Table I). A number of patients had a combination of these problems. Twelve patients were examined during laparotomy before opening the bowel (Espiner, Salmon, Teague, and Read, 1972).

In all cases a history, clinical examination, proctosigmoidoscopy, and radiology preceded fibreoptic endoscopy.

\section{Preparation of the Patient}

Thirty consecutive patients were randomly allocated either to a commercially prepared non-residue liquid 


\begin{tabular}{ll}
\hline Indication & No. of Patients \\
\hline Rectal bleeding & 75 \\
Non-specific diarrhoea & 52 \\
Assessment of inflammatory bowel disease & 55 \\
Equivocal radiology alone & 17 \\
Anaemia, weight loss, abdominal pain, etc & 56 \\
\hline
\end{tabular}

Table I Indications for fibreoptic colonoscopy ${ }^{1}$

${ }^{1}$ In each case the indication has been noted under the major referring problem as assessed by the physician or surgeon in charge of the case.

diet (1800 calories daily) (Vivasorb) or to a lowresidue liquid diet prepared by the Dietetics Department of Bristol Royal Infirmary. Both diets were prescribed for five days. Both diets were equally effective in producing a reasonably clean bowel for total colonoscopy.

Subsequently, however, an extended technique has been developed based on the St Mark's Hospital procedure, as follows:

DAY 1

Low-residue diet

DAY 2

Low-residue diet (liquid)

For patients with proven or suspected colitis: magnesium citrate solution $50 \mathrm{ml}$ two hourly $\times 6$, beginning at $9 \mathrm{am}$; for all other patients: castor oil $30 \mathrm{ml}$ at midday. A 5-litre tap-water enema is given at $10 \mathrm{pm}$.

DAY 3

A 5-litre tap-water enema one hour before examination.

This procedure has been found to be extremely effective. The importance of good bowel preparation before colonoscopy cannot be overemphasized.

Analgesia was reqiured in the majority of cases. For left-sided examination premixed nitrous oxide and oxygen (Entonox, British Oxygen Company) was used as previously described (Bennett, Salmon, Branch, Baskett, and Read, 1971).

For total colonoscopy intravenous diazepam (Valium, Roche) was employed in addition to Entonox. Hyoscine-N-butyl bromide (Buscopan) $40 \mathrm{mg}$ intravenously was employed where spasm limited the extent of examination.

\section{Endoscopic Technique}

Colonoscopy may be performed in an examination room without special facilities but should ideally be carried out with radiological screening facilities. We employ a Philips BV $20 \mathrm{~S} 15 \mathrm{~cm}$ image intensifier allowing fluoroscopy up to $100 \mathrm{kv}$ under normal lighting conditions. There is little doubt that with increasing experience screening facilities are required less and less.

For left-sided examination the entire procedure is carried out in the left lateral position. Total colonoscopy is commenced in the left lateral position but this may be changed to the prone or supine position during the examination if required.

The instrument is advanced under direct vision by a combination of persuasive pressure, rotation, and distal tip manipulation. The instrument is advanced only when mucosa is seen to move past the instrument tip. If the mucosa blanches the instrument is withdrawn. Particular care should be taken to pass the rectosigmoid junction under direct vision.

It may be difficult to advance the instrument beyond the upper sigmoid colon when anatomical variations such as an S-shaped or U-shaped sigmoid are encountered. In these situations the tip of the instrument should be hooked around a flexure and the instrument withdrawn and rotated through $90^{\circ}$ until the sigmoid loop is seen by fluoroscopy to be straightened. This manoeuvre is required in about $15 \%$ of patients and may be facilitated by the insertion of 20 gauge piano wire into the biopsy channel to stiffen the instrument when the manoeuvre is completed. With experience these types of sigmoidoscopic configuration can be recognized endoscopically and straightening manoeuvres carried out without fluoroscopic control. A similar type of hook and withdrawal manoeuvre is used whenever redundant loops of colon render direct advancement difficult (Deyhle and Demling, 1971).

When the caecum is reached the appendix orifice and ileocaecal valve may be visualized. The ileocaecal valve has a number of constantly changing configurations and if difficulty is encountered identifying it a cup of warm tea given to the patient with $10 \mathrm{mg}$ metaclopramide iv (Maxolon) will promote influx of ileal contents into the caecum (Williams, 1972a). When the instrument has negotiated several acute flexures it may be difficult to pass the biopsy forceps to the full length of the instrument. Before the examination the terminal part of the biospy channel is lubricated by passing the forceps down the instrument and protruding the tip for about $10 \mathrm{~cm}$. This is then generously lubricated with silicone oil (Dow-Corning) and then withdrawn through the instrument (Eddy, 1972).

\section{Results}

One hundred and two examinations were performed for total colonoscopy. Of these, 47 examinations reached the caecum ( $46 \%$ ). However, 18 examinations were stopped because an occluding lesion was found before the caecum was reached. The success 
rate for total colonoscopy is therefore approximately $64 \%$.

Reasons for failure to reach the caecum were poor preparation $(20 \%)$ and the patient's distress and poor technique $(16 \%)$.

The average time taken for total colonoscopy was 60 minutes and for left-sided colonoscopy 20 minutes.

Endoscopic findings are shown in Table II.

\begin{tabular}{ll}
\hline Proctocolitis & 55 \\
Crohn's disease & 16 \\
Polyps & 17 \\
Carcinoma & 22 \\
Normal bowel & 99 \\
Diverticular disease & 15 \\
Operative findings & 12 \\
Others (melanosis coli, amoebiasis, strictures, etc) & 19 \\
\hline
\end{tabular}

Table II Endoscopic findings

A definitive diagnosis was made by endoscopic examination alone in $26.5 \%$ of cases (Table III).

\section{Carcinoma}

Polyps

Inflammatory bowel disease

Traumatic ulcer

Total

Table III Diagnosis made solely by colonoscopy

(26.5\% of total cases referred)

The radiological diagnosis was refuted in 11 patients and an unnecessary laparotomy avoided in seven of these (Table IV).

\section{Polyps}

Carcinoma

Colitis

Crohn's disease

Stricture

Table IV Refuted large bowel radiology

Thirty-eight $(50 \%)$ of the patients examined because of rectal bleeding had the site of bleeding identified by fibreoptic examination (Table $\mathrm{V}$ ).

\begin{tabular}{lc}
\hline Diagnosis by Colonoscopy & No. of Cases \\
\hline Carcinoma & 14 \\
Polyps & 7 \\
Inflammatory bowel disease & 15 \\
Diverticulitis & 1 \\
Haemorrhoids & 1 \\
Total & 38 \\
\hline
\end{tabular}

Table V Rectal bleeding (75)

\section{Discussion}

There is now little doubt that the wider use of fibreoptic endoscopes for the investigation of large bowel disease has increased diagnostic accuracy. (Niwa, Utsumi, Nakamura, Yoshida, Yoshitoshi, Fujino, Kaneko, Kasumi, and Matsumoto, 1969; Hansen, 1971; Deyhle and Demling, 1971; Salmon et al, 1971; Williams and Muto, 1972).

Our own results in 51 patients (Salmon et al, 1971) showed that endoscopy alone made the diagnosis in $23 \%$ of cases and now in a much larger series, in $26.5 \%$ of cases. This supports the experience of other centres (Williams and Muto, 1972).

Rectal bleeding accounted for 75 of our case referrals (Table I). All these patients had had a full clinical examination, digital examination of the rectum, proctosigmoidoscopy, and large bowel radiology. Double-contrast radiographs were not employed routinely. In $38(50 \%)$ of these patients pathology was detected by endoscopy alone. It is possible that this high detection rate would have been lower if double-contrast barium enemas had been performed routinely (Wiliams, 1972b). We consider this group one of the most important indications for endoscopy.

Non-specific diarrhoea (52 cases) included patients who were finally diagnosed as the irritable bowel syndrome. The decision to perform colonoscopy was dictated by the referring clinician who had a high index of suspicion of organic bowel disease after routine investigations had produced normal results.

Assessment of inflammatory bowel disease was the referring request in 55 patients. In the case of ulcerative colitis endoscopic evidence of inflammatory bowel disease (Baron, Connell, and LennardJones, 1964) did not always correspond with the extent of disease suggested by a recent barium enema. With Crohn's disease (16 cases) the presence and extent of large bowel involvement was similarly more easily documented by endoscopy. The stiffer colon of chronic inflammatory disease allowed total colonoscopy in nearly all these cases.

Seventeen patients were examined because of the radiologist's doubt as to the presence or absence of pathology. In 11 of these cases endoscopy refuted the radiologist's provisional diagnosis (see Table IV) so that either a repeat barium examination or exploratory laparotomy was avoided.

Of the 60 patients (Table III) in whom colonoscopy alone provided a diagnosis, 17 cases of unsuspected cancer were detected. Five further cases of cancer with radiologically detected lesions were studied in order to perform a preoperative check that there were no further lesions and in addition to obtain a tissue diagnosis. 
Fifteen patients were found to have one or more polyps which had hitherto escaped diagnosis. Although the malignant potential of adenomatous polyps of the colon has been questioned, their association with carcinoma is well known and it is probable that both lesions arise in response to a common stimulus (Castleman and Krickstein, 1962). The importance of examining the whole colon in these cases is evident. In those cases where total colonoscopy was not possible preoperatively, total operative colonoscopy was performed on the unopened bowel at laparotomy before colotomy and polypectomy (Espiner et al, 1972).

We feel that the value of total colonoscopy lies in specially selected patients such as those in whom radiology of the caecal pole is incomplete and in those where suspected ileocaecal pathology requires visual confirmation with a tissue diagnosis. Total colonoscopy may also be indicated in the search for polyps and in rectal bleeding where the source is right-sided. In addition it may be used for determining the status and extent of inflammatory bowel disease and for screening chonic cases for malignant change.

We have not had experience of polypectomy using the colonoscope although this is being practised in some centres in the USA (Shinya and Wolff, 1972; Eddy, 1972) and in at least one centre in Britain (Williams, 1972a).

Complications are rare. We have perforated the lower sigmoid colon in one patient with marked irradiation colitis who presented with rectal bleeding; laparotomy with suture was uneventful. We consider that colonoscopy should not be performed under general anaesthesia except during laparotomy when the surgeon can guide the tip of the instrument without opening the bowel.

In our experience the long colonoscopes are less reliable but nevertheless a well equipped unit should have both a long and a short or medium length instrument.
We would like to thank the physicians and surgeons of the United Bristol Hospitals for referring patients to us. We also thank Dr J. Roylance and Dr R. J. Burwood for expert radiological advice. We thank Miss C. Neumann for skilled endoscopic nursing.

In addition we would like to thank Mrs R. Ward and Miss P. Champion of the Dietetics Department, Bristol Royal Infirmary, for their assistance.

References

Baron, J. H., Connell, A. M., and Lennard-Jones, J. E. (1964). Variation between observers in describing mucosal appearances in proctocolitis. Brit. med.J., 1, 89-92.

Bennett, J. A., Salmon, P. R., Branch, R. A., Baskett, P. J. F., and Read, A. E. (1971). The use of inhalational analgesia during fibre-optic colonoscopy. Anaesthesia, 26, 294-297.

Castleman, B., and Krickstein, H. I. (1962). Do adenomatous polyps of the colon become malignant? New Engl. J. Med., 267, 469 . 475.

Classen, M. (1971). Fibre-endoscopy of the intestines. Gut, 12, 330-337.

Dean, A. C. B., and Shearman, D. J. C. (1970). Clinical evaluation of a new fibreoptic colonoscope. Lancet, 1, 550-552.

Deyhle, P., and Demling, L. (1971). Coloscopy-technique, results, indications. Endoscopy, 3, 143-151.

Eddy, H. J. (1972a). Personal communication.

Eddy, H. J. (1972b) Intracolonic electro-snare polypectomy using flexible fiberoptic colonoscopes. In Proceedings of the 2nd European Congress of Digestive Endoscopy, Paris.

Espiner, H. J., Salmon, P. R., Teague, R. H., and Read, A. E. (1972). Operative colonoscopy. (To be published).

Hansen, L. K. (1971). Colonoscopy: a study of 50 cases. Scand. J. Gastroent., 6, 687-691.

Niwa, H., Utsumi, Y., Nakamura, T., Yoshida, A., Yoshitoshi, Y., Fujino, M., Kaneko, E., Kasumi, A., and Matsumoto, M. (1969). Clinical experience of colonic fiberscope. Gastroent. Endosc. (Tokyo), 11, 163-173.

Salmon, P. R., Branch, R. A., Collins, C., Espiner, H., and Read, A. E. (1971). Clinical evaluation of fibreoptic signoidoscopy employing the Olympus CF-SB colonoscope. Gut, 12, 729-735.

Shinya, H., and Wolff, W. I. (1972). Therapeutic applications of colonfiberoscopy: Polypectomy via the colonoscope In Proceedings of the 2nd European Congress of Digestive Endoscopy, Paris.

Williams, C. (1972a). Use of long colonoscope for examination of whole colon and for polypectomy. Proc. roy. Soc. Med., 65, 967.

Williams, C. (1972b). Personal communication.

Williams, C., and Muto, T. (1972). Examination of the whole colon with the fibreoptic colonoscope. Brit. med.J., 3, 278-281. 